\title{
Pathogenicity of mouse hepatitis virus for preimplantation mouse embryos
}

\author{
P. Carthew, Maureen J. Wood and Carol Kirby \\ MRC Experimental Embryology \& Teratology Unit, Woodmansterne Road, Carshalton, \\ Surrey SM5 4EF, U.K.
}

\begin{abstract}
Summary. Mouse embryos which were hatched from the zona pellucida in vitro in the presence of mouse hepatitis virus (MHV) or outgrown on coverslips and then exposed to MHV were shown by immunohistochemical staining to have virally infected trophoblast cells. Zona-intact embryos incubated with MHV for $48 \mathrm{~h}$ (2-cell embryos) or $1.5 \mathrm{~h}$ (blastocysts) were resistant to infection. Morulae and early blastocysts collected from donor mice experimentally infected with MHV were not infected, but the medium in which they were flushed from the uterine horns was contaminated with virus. No virus was detected after embryos were washed through three changes of uncontaminated medium. MHV was transmitted to foster mothers when embryos were transferred in medium contaminated with the virus. Fetal and decidual tissues were not infected. We suggest that embryo transfer is an effective and simple alternative to Caesarian rederivation of MHV-contaminated mice.
\end{abstract}

\section{Introduction}

Embryo transfer is used increasingly to supplement or replace hysterectomy rederivation of animals in relation to microbiological contamination, and after the recovery of frozen embryos from embryo banks (Whittingham, 1979). It is pertinent to examine the efficacy of the technique in preventing the transmission of viral diseases during transfer of murine embryos collected from infected donors. Tuffrey, Zisman \& Barnes (1972) reported that preimplantation mouse embryos could be infected with Sendai virus but subsequently this was not confirmed (Neighbour, 1977; Carthew, Wood \& Kirby, 1983). Zona-intact embryos are not susceptible to infection with minute virus of mice (MVM; Mohanty \& Bachmann, 1974), murine cytomegalovirus (MCMV), or lactate dehydrogenase virus (Neighbour, 1977), but MVM infects embryos when the zonae pellucidae are removed by pronase treatment (Mohanty \& Bachmann, 1974). The exposure of zona-free blastocysts to MCMV resulted in fetal loss after embryo transfer and the virus was isolated from the foster mothers (Baskar \& Huang, 1981).

Neighbour (1977) found that coxsackie B3 infected and destroyed preimplantation mouse embryos, but this virus is not a natural infection of mice. Lymphocytic choriomeningitis virus can infect zona-intact ova and cross the placenta during persistent infection (Mims, 1966). Because of the zoonotic hazard this virus has been eliminated from breeding colonies (Carthew \& Verstraete, 1978 ) and therefore it would not be encountered in routine embryo transfer.

Mouse hepatitis virus (MHV) is widespread in mouse colonies (Gannon \& Carthew, 1980) where it occurs subclinically, except in young (pre-weaning; Carthew, 1977) and immunodeficient (Carthew, 1978) mice. It can be a clinical problem in colonies in which the immunodeficient nude mouse is maintained (Sebesteny \& Hill, 1974; Tamura, Ueda, Hirano \& Fujiwara, 1976; Ward, Collins \& Parker, 1977). We have examined the possibility of MHV being transmitted during

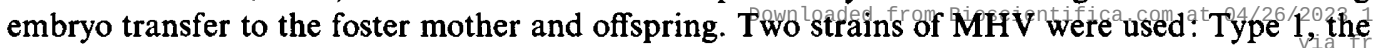


avirulent strain which is endemic in the United Kingdom (Carthew, 1978, 1981a) and the more pathogenic strain A59 (Manaker, Piczak, Miller \& Stanton, 1961).

\section{Materials and Methods}

Source and collection of embryos. Groups of MHV-infected and uninfected immature random-bred MF1 mice were induced to superovulate by intraperitoneal injection of 5 i.u. PMSG (Folligon: Intervet, Cambridge, U.K.) followed 48 h later by 5 i.u. hCG (Chorulon: Intervet). After the hCG injection the mice were paired with MF1 males and examined the next morning for copulation plugs (Day 1 of pregnancy). Embryos were flushed from the oviducts on Day 2 (2-cell) or from the uterine horns on Day 4 (morulae and early blastocysts) with a modified Krebs-Ringer mouse embryo culture medium containing Hepes buffer (M2; Quinn, Barros \& Whittingham, 1982). At each collection the embryos were pooled in Medium M2; then washed in three changes of Medium M2 (2 ml per wash). Samples of the embryos and each wash solution were tested for the presence of virus.

Virus. Mouse hepatitis virus strains 1 and A59 were obtained from the American Type Culture Collection, Rockville, Maryland, U.S.A., and propagated and titrated in NCTC 1469 cells as described by Carthew \& Sparrow (1981).

Experiment 1: administration of hepatitis virus to embryo donors. Type A59 mouse hepatitis virus containing $10^{3} \mathrm{TCD}_{50}\left(10^{3}\right.$ tissue culture $50 \%$ infectious doses $)$ was inoculated intranasally $(0.025$ $\mathrm{ml}$ ) into the embryo donors before superovulation. Ovulation was induced so that Day-4 embryos were collected on Day 7 of the virus infection, at which time liver lesions due to the virus infection are well established (Carthew \& Sparrow, 1981). Intranasal infection was chosen because (1) it is probably the route of natural transmission, and (2) it avoided the introduction of virus directly into the peritoneal cavity, where it might have persisted and subsequently contaminated the uterine horns without systemic dissemination. The infected mice were housed in a negative-pressure isolator. Control mice in Exp. 1 were dosed with a suspension of NCTC 1469 cell lysate from cells not infected with virus and treated in parallel with the infected group.

Experiment $2:$ infection of preimplantation embryos and blastocyst outgrowths with mouse hepatitis virus. The zonae pellucidae were removed from Day-4 embryos with acidic Tyrode's solution ( $\mathrm{pH}$ 2.5 , adjusted with $0.2 \mathrm{~N}-\mathrm{HCl}$; Nicolson, Yanagimachi \& Yanagimachi, 1975). After washing through several changes of Medium M2, zona-free morulae and blastocysts were incubated in a bicarbonate-buffered mouse embryo culture medium (No. 16; Whittingham, 1971) containing MHV A59 $\left(10^{3} \mathrm{TCD}_{50} / \mathrm{ml}\right)$ at $37^{\circ} \mathrm{C}$ in an atmosphere of $5 \% \mathrm{CO}_{2}$ in air. After $90 \mathrm{~min}$, half of the embryos were transferred directly to Medium 16 supplemented with $10 \%$ fetal calf serum and culture was continued. The remaining embryos were rinsed through 3 changes of Medium $16(2 \mathrm{ml}$ per wash) before culture in supplemented Medium 16. Embryos were observed daily for 3 days and aliquants of medium were removed and assayed for infectious virus as described below.

A group of zona-intact blastocysts collected from uninfected donors were cultured for $72 \mathrm{~h}$ on glass coverslips in Minimum Essential Medium (MEM: Gibco Europe Ltd, Paisley, Scotland) supplemented with $10 \%$ fetal calf serum at $37^{\circ} \mathrm{C}$ in an atmosphere of $5 \% \mathrm{CO}_{2}-95 \%$ air, to form outgrowths. The outgrowths were infected by overlaying with $0.5 \mathrm{ml}$ of $10^{3}$ or $10^{2} \mathrm{TCD}_{50}$ of MHV 1 or MHV A59. After $24 \mathrm{~h}$ the outgrowths were washed in phosphate-buffered saline $(\mathrm{pH} 7.4)$ and fixed in $95 \%$ ethanol. Other zona-intact Day-4 blastocysts collected from uninfected donors were cultured for $72 \mathrm{~h}$ in MEM with $10 \%$ fetal calf serum containing $10^{3}$ or $10^{2} \mathrm{TCD}_{50}$ of MHV 1 or MHV A59. Any that outgrew were fixed in $95 \%$ ethanol. All fixed embryonic outgrowths were examined for the presence of $\mathrm{MHV}$ replication by the indirect immunoperoxidase technique (Carthew, 1978). After immunoperoxidase staining embryonic outgrowths were counterstained with Harris' haematoxylin before mounting in aqueous mounting medium. As controls for the 
staining of MHV-infected cells, uninfected embryos were outgrown and tested with antiserum that was specific for $\mathrm{MHV}$, as well as with sera containing no antibodies to MHV. Outgrowths shown to be infected by immunoperoxidase staining, were tested with mouse sera containing no MHV antibodies. None of the controls showed positive staining.

Experiment 3 : in-vitro incubation with $M H V$ before embryo transfer. Two-cell embryos collected from uninfected donors were cultured in Medium 16 containing MHV A59 $\left(10^{3} \mathrm{TCD}_{50} / \mathrm{ml}\right)$ at $37^{\circ} \mathrm{C}$ in a humidified atmosphere of $5 \% \mathrm{CO}_{2}-95 \%$ air. The culture medium was overlaid with paraffin oil and was renewed daily. After $48 \mathrm{~h}$ morphologically normal morulae and blastocysts were washed through 3 changes of Medium M2 and transferred to pseudopregnant recipients. The remaining normal and all the degenerate embryos were washed and then tested for the presence of virus.

Morulae and early blastocysts collected from virus-free donors were incubated in Medium M2 containing MHV A59 $\left(10^{3} \mathrm{TCD}_{50} / \mathrm{ml}\right)$ for $90 \mathrm{~min}$ at $37^{\circ} \mathrm{C}$ in air before embryo transfer. Half of the embryos were washed in Medium M2 $(3 \times 2 \mathrm{ml})$ before transfer and the remainder were transferred without washing.

Control embryos were incubated in the appropriate medium (No. 16 or M2) without MHV. Experimental and control samples were handled by different experimenters and cultured separately.

Embryo transfer. Morulae and blastocysts were transferred to the uterine horns (5-6 embryos/horn) of Day-3 pseudopregnant (CBA/NIMR $\times$ C57BL/NIMR) F1 hybrid females. Pseudopregnancy was induced in the recipients by mating with a sterile male. To minimize the risk of accidental contamination, in each experimental replicate control embryos were transferred before the experimental embryos. After embryo transfer the recipients were housed in negativepressure isolators. Foster mothers were killed on Day 10 or Day 15 of gestation or were allowed to litter. Litters were weaned 21 days post partum. At autopsy on Day 10 or 15 of pregnancy the implantation sites and normal fetuses were counted. Maternal liver and fetal and decidual tissues were screened for the presence of virus as described below. The recipients that weaned litters were killed with their offspring at 3 or 6 weeks post partum. Mothers and weanlings were serologically screened for the presence of antibody to MHV, using the complement fixation test (Gannon \& Carthew, 1980) and ELISA test (Carthew, Gannon \& Whisson, 1981).

Virus isolation from embryos, washing media and tissue samples. Two methods were used to detect virus. Embryos collected from mice infected with MHV A59 or from control mice and embryos cultured with MHV in vitro were homogenized and frozen and thawed three times. Aliquants of the homogenates and of the medium used to wash the embryos were overlayed on mouse L929 cells. When infected with MHV, mouse L929 cells form characteristic multinucleate giant cells (syncytia) in which as many as 20 nuclei are easily recognized (Pl. 1, Fig. 1). Aliquants of washing medium, homogenized frozen and thawed embryos or homogenized tissues were also injected intraperitoneally into nude mice. Because of their T-cell immunodeficiency, nude mice are very sensitive to MHV and any virus present in the injected samples undergoes repeated replication cycles (Carthew, 1981b). Mice that died during the 2 weeks after injection were examined histologically to confirm MHV infection (Carthew \& Sparrow, 1981) and at the end of 2 weeks all surviving mice were examined histologically for MHV infection.

\section{Results}

\section{Experiment 1}

Acute MHV infection in the donor mice had no effect on the yield of morphologically normal morulae and early blastocysts: 288 normal embryos were flushed from 12 infected mice and 293 from 11 control animals. When the embryos from infected donors and the medium used for washing the embryos were examined for the presence of virus none was present on the embryos washed 
Table 1. Recovery of MHV by tissue culture isolation or animal transmission test from embryos and washings during flushing of mouse uteri on Day 4 of pregnancy

\begin{tabular}{|c|c|c|c|c|c|c|c|c|}
\hline & \multicolumn{4}{|c|}{ Tissue culture isolation ${ }^{*}$} & \multicolumn{4}{|c|}{ Nude mouse transmission test } \\
\hline & Wash 1 & Wash 2 & Wash 3 & $\begin{array}{c}\text { Morulae } \\
\text { and } \\
\text { blastocysts }\end{array}$ & Wash 1 & Wash 2 & Wash 3 & $\begin{array}{l}\text { Morulae } \\
\text { and } \\
\text { blastocysts }\end{array}$ \\
\hline MHV-infected & $4 \times 10^{3}$ & $2 \times 10$ & - & - & + & + & - & - \\
\hline Control & - & - & - & - & - & - & - & - \\
\hline
\end{tabular}

* Virus titre expressed in syncytia-forming units per $\mathrm{ml}$.

- No virus detected; + virus detected.

through 3 changes of Medium M2, but large amounts were present in the preliminary washing media (Table 1). This suggests that the embryos are not productively infected with virus, but that virus is present in the peritoneum and is transferred on the uterine horns into the flushing medium or that virus is present in oviducal fluid. As the embryos were washed in successive changes of Medium M2 the amount of virus present was diluted out. No virus was detected on embryos from the uninfected donors.

\section{Experiment 2}

The possibility of virus being present when embryos collected from infected females are transferred to foster mothers or outgrown for the development of cell lines, led us to investigate the effect of MHV on embryos allowed to outgrow in vitro.

When blastocysts were exposed for $72 \mathrm{~h}$ in vitro to MHV 1 or A59 there was an obvious cytopathic effect on the trophoblast cells: $90 \%$ of virus-exposed embryos did not form outgrowths after hatching because the trophoblast cells were necrotic. When tested by the indirect immunoperoxidase technique the surviving embryos that did form outgrowths were positive for MHV replication. Similarly outgrowths that had been allowed to form $72 \mathrm{~h}$ before infection with MHV 1 or A59 were positive for MHV replication. For both viruses the trophoblast cells fused to form syncytia characteristic of MHV infection. Furthermore, all syncytia (and also some non-fused trophoblast cells) were positive for MHV replication (Pl. 1, Fig. 2).

Zona-free blastocysts cultured with MHV and then washed to remove unbound virus fared no better than embryos allowed to hatch in medium containing MHV. These blastocysts degenerated during incubation for 3 days after washing and $\mathrm{MHV}$ was released into the culture medium, giving a 100 -fold increase in virus after 3 days of culture.

\section{Experiment 3}

Two-cell embryos were incubated in vitro with MHV for $48 \mathrm{~h}$ and then washed before embryo transfer. In the control and virus-exposed groups $74 \%$ of embryos reached the 8-cell stage after $24 \mathrm{~h}$ (Table 2). After $48 \mathrm{~h}$ significantly more control (93\%) than MHV-exposed (86\%) embryos formed morulae or early blastocysts ( $G=13.308 ; P<0.01$; Sokal \& Rohlf, 1969). However, after embryo transfer the percentage of embryos that implanted and formed normal fetuses by Days 10 and 15 of gestation and the percentage of liveborn offspring were similar in the control and experimental groups (Table 3). By necessity the embryos were cultured in different incubators and this may explain the slight retardation observed in the in-vitro development of the virus-exposed embryos. No virus was isolated from any Day- 10 or Day- 15 fetuses and sera from the foster mothers and their litters were negative for antibody to MHV. Virus was not isolated from the samples of normal and degenerate embryos tested after washing. 


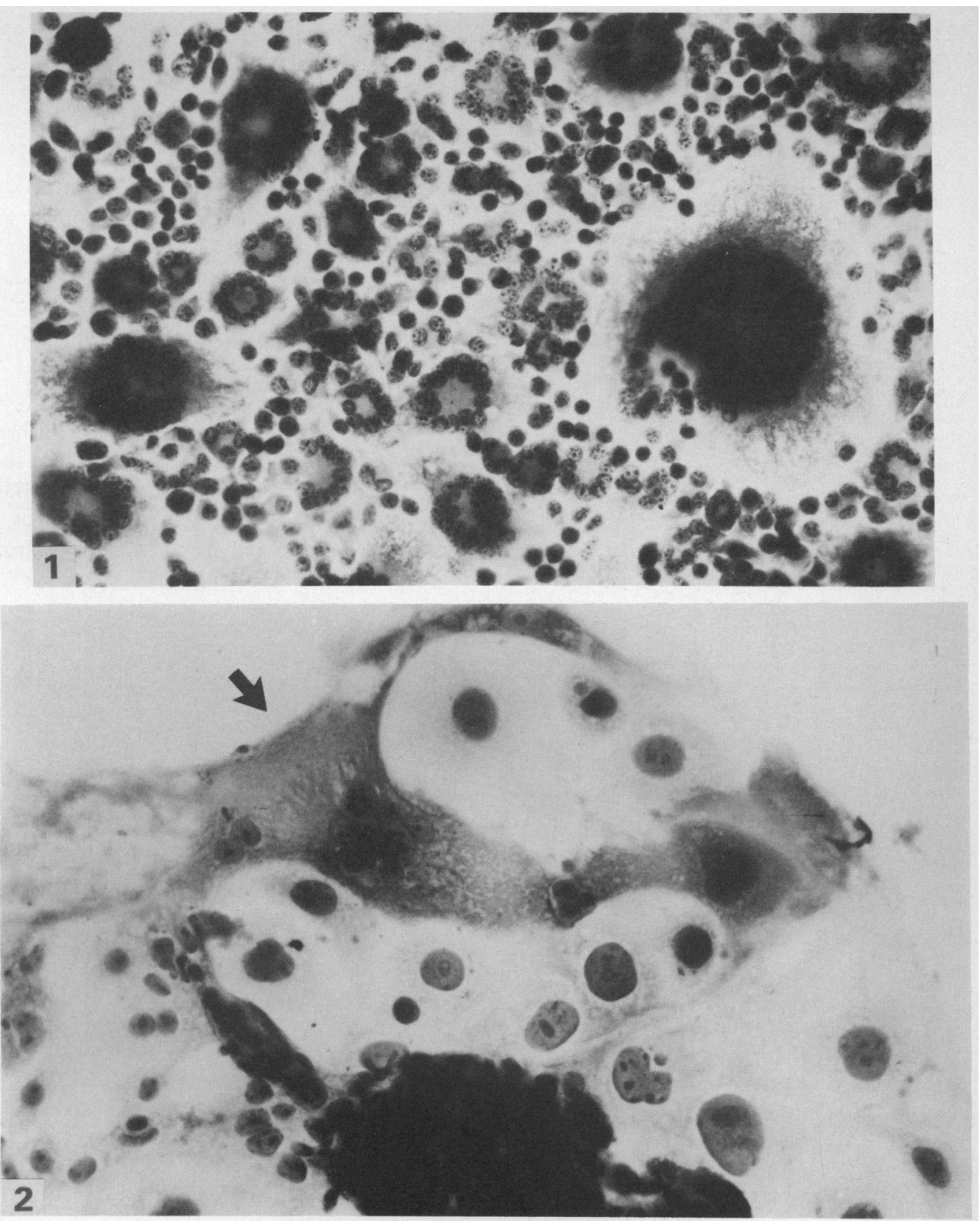

Fig. 1. Numerous giant cells (syncytia) formed due to mouse hepatitis infection and cell fusion of $\mathbf{L} 929$ cells. $\times 170$.

Fig. 2. Immunoperoxidase staining of outgrown mouse blastocysts infected with mouse hepatitis virus. Note staining of syncytium (arrowed) and one other cell due to the replication of MHV intracellularly. $\times 340$. 
Table 2. Development of mouse embryos cultured in vitro for $48 \mathrm{~h}$ from the 2-cell stage in medium containing MHV

Developmental stage reached

\begin{tabular}{|c|c|c|c|c|c|c|c|c|c|}
\hline \multirow[b]{2}{*}{$\begin{array}{l}\text { Culture } \\
\text { medium }\end{array}$} & \multirow{2}{*}{$\begin{array}{c}\text { No. of } \\
\text { 2-cell } \\
\text { embryos } \\
\text { cultured }\end{array}$} & \multicolumn{4}{|c|}{ After $24 \mathrm{~h}$} & \multicolumn{4}{|c|}{ After $48 \mathrm{~h}$} \\
\hline & & $\begin{array}{c}\text { No. } \\
\text { scored* }\end{array}$ & 8-cell & 2-7-cell & Degenerate & $\begin{array}{l}\text { No. } \\
\text { scored* }\end{array}$ & $\begin{array}{l}\text { Morula or } \\
\text { blastocyst }\end{array}$ & 3-8-cell & Degenerate \\
\hline $\begin{array}{l}\text { No. } 16 \\
\text { (control) }\end{array}$ & 531 & 531 & 396 & 132 & 3 & 531 & 494 & 25 & 12 \\
\hline $\begin{array}{l}\text { No. } 16 \\
+\mathrm{MHV}\end{array}$ & 530 & 516 & 380 & 119 & 17 & 490 & 422 & 45 & 23 \\
\hline
\end{tabular}

Values are for 2 replicates.

* A total of 40 experimental embryos was lost during handling.

Table 3. Effect on the outcome of embryo transfer of culturing 2-cell mouse embryos with MHV for $48 \mathrm{~h}$ or of exposing blastocysts to MHV for $1.5 \mathrm{~h}$ before transfer

\begin{tabular}{|c|c|c|c|c|c|c|c|c|c|}
\hline \multirow{2}{*}{$\begin{array}{l}\text { Embryonic } \\
\text { stage } \\
\text { cultured }\end{array}$} & \multirow[b]{2}{*}{ Medium } & \multirow{2}{*}{$\begin{array}{c}\text { Time } \\
\text { in } \\
\text { culture } \\
\text { (h) }\end{array}$} & \multirow{2}{*}{$\begin{array}{l}\text { Wash } \\
\text { in M2 } \\
\text { before } \\
\text { transfer }\end{array}$} & \multirow{2}{*}{$\begin{array}{l}\text { No. of } \\
\text { embryos } \\
\text { transferred }\end{array}$} & \multirow{2}{*}{$\begin{array}{l}\text { No. of } \\
\text { recipients }\end{array}$} & \multicolumn{2}{|c|}{$\%$ Implanted $\dagger$} & \multirow{2}{*}{$\begin{array}{c}\% \text { Normal } \\
\text { fetuses on } \\
\text { Day } 15 \dagger\end{array}$} & \multirow{2}{*}{$\begin{array}{c}\% \\
\text { Liveborn }\end{array}$} \\
\hline & & & & & & Day 10 & Day 15 & & \\
\hline \multirow[t]{6}{*}{ 2-cell } & MHV & 48 & + & 60 & $5^{*}$ & 96 & - & - & - \\
\hline & & & + & 60 & 5 & - & 93 & 67 & - \\
\hline & & & + & 84 & $7^{*}$ & - & - & - & 51 \\
\hline & Control & 48 & + & 48 & 4 & 92 & - & - & - \\
\hline & & & + & 48 & 4 & - & 83 & 67 & - \\
\hline & & & + & 72 & 6 & - & - & - & 57 \\
\hline \multirow[t]{9}{*}{ Blastocyst } & MHV & 1.5 & + & 40 & 4 & 100 & - & - & - \\
\hline & & & + & 40 & 4 & - & 100 & 100 & - \\
\hline & & & + & 78 & 8 & - & - & - & 90 \\
\hline & MHV & 1.5 & - & 40 & 4 & 85 & - & - & - \\
\hline & & & - & 39 & 4 & - & 100 & 90 & - \\
\hline & & & - & 80 & 8 & - & - & - & 90 \\
\hline & Control & 1.5 & - & 29 & 3 & 83 & - & - & - \\
\hline & & & - & 29 & $3^{*}$ & - & 95 & 95 & - \\
\hline & & & - & 39 & 4 & - & - & - & 72 \\
\hline
\end{tabular}

Values are totals of 2 replicates.

* One recipient failed to maintain pregnancy.

$\dagger$ As no. of embryos transferred to pregnant females.

Freshly collected blastocysts were exposed to MHV for $90 \mathrm{~min}$ to allow any possible binding to the zona pellucida. Half of the embryos were washed 3 times in fresh medium before transfer and the remainder were transferred in the medium containing MHV. Control embryos were held in Medium M2 before transfer. The outcome of the transfers is shown in Table 3. The number of embryos implanting and forming normal fetuses and the number of live births was not significantly different in the group receiving virus-contaminated embryos compared to the controls. No virus was isolated from fetal or decidual tissues in any of the groups. This is consistent with the fetuses not being infected in utero. However, virus was isolated from the livers of foster mothers receiving embryos in MHV-contaminated medium and there were histological lesions of MHV infection in liver sections taken from foster mothers on Day 10 but not Day 15 of pregnancy. Recipients of embryos in contaminated medium and their offspring showed a serological response when tested 3 
weeks after birth of the litters. The serological titres were comparable in mothers and litters ( 1 in 80 ). Litters sampled 6 weeks post partum showed a diminished serological titre compared to the respective foster mother (mother, 1 in 80 ; litter, 1 in 20 ), which is consistent with the litters having maternal antibody protection due to the response of the foster mother to primary infection. The decrease in antibody titre at 6 weeks in the litters is also consistent with a natural decline in maternal antibody after weaning. No antibody was isolated from the control mice receiving washed blastocysts.

\section{Discussion}

There is no evidence that $\mathrm{MHV}$ is present in the reproductive tract during acute infection, and it would be difficult, if not impossible, to test for this because of the risk of contaminating the contents of the uterus during removal from the infected peritoneum. Our results show that virus, presumably shed from the liver into the peritoneal cavity, is transferred with the excised uterine horns to the handling medium (Table 1). This creates the risk of subsequent infection of the embryo during in-vitro culture or transfer of virus with the embryo to recipient foster mothers. Previous work on the experimental infection of preimplantation embryos with viruses has shown that mouse ova are susceptible to lymphocytic choriomeningitis virus, (Mims, 1966) and that, experimentally, MVM can infect preimplantation embryos, but only if the zona is removed (Mohanty \& Bachmann, 1974). Similarly, we found that mouse embryos are susceptible to infection with MHV only after removal of the zona. Of the other commonly encountered murine viruses, Sendai virus does not infect preimplantation embryos in vitro (Neighbour, 1977) or in vivo, (Carthew et al., 1983) and has no effect on the outcome of embryo transfer in mice (Carthew et al., 1983). Many attempts to infect preimplantation mouse embryos with murine cytomegalovirus have failed (Neighbour, 1977).

The transfer of blastocysts microinjected with MCMV into the uteri of mice resulted in infection of the implantation sites (Baskar \& Huang, 1981), presumably because this virus is able to infect trophectoderm cells after the blastocyst hatches from its protective zona. Our results (Exp. 2) suggest that MHV could behave similarly. The trophoblast cells of blastocysts hatching in vitro became infected with MHV, and the resulting cytopathic effect, if it occurred in vivo, would prevent implantation. However, further data (Exp. 3) show that if virus is present with embryos during transfer it does not inhibit implantation and the decidual and fetal tissue are not infected. Presumably the virus is excreted from the reproductive tract before zona lysis occurs and then infects the foster mother who exhibits typical liver lesions and a strong serological response. The litter is protected by maternal antibody from infection post partum. From a practical point of view this means that the infection has not been eliminated, as the foster mother is acutely infected and can excrete infectious virus which will be transmitted to other susceptible mice. Given the widespread nature of MHV strains in experimental mouse colonies throughout the world this effect could be serious. However, this is an extreme case. We have shown that zona-intact embryos are not affected when exposed to MHV in vitro and that repeated washing of intact embryos in fresh medium reduces the risk of contamination. Nonetheless the risks should be borne in mind when preparing embryos, whether for outgrowth and preparation of cell lines (Evans \& Kaufman, 1981), for embryo transfer or for storage in frozen embryo banks.

One of the major advantages of embryo transfer is that it could eliminate micro-organisms which are able to cross the placenta. MHV is known to be transmitted in this way (Katami, Taguchi, Nakayama, Goto \& Fujiwara, 1978) when dams have been intravenously inoculated with virus. We suggest that even when acutely infected mice are used as embryo donors, the possibility of infection of the embryos and resulting fetuses is small. Thus embryo transfer is a suitable alternative to Caesarian section for the rederivation of MHV-free colonies.

We thank Dr David Whittingham for helpful suggestions and Miss Henrietta Lee for typing the manuscript. 


\section{References}

Baskar, J.F. \& Huang, E.S. (1981) Effects of murine cytomegalovirus on implantation stage mouse embryos. Proc. Soc. exp. Biol. Med. 167, 581-587.

Carthew, P. (1977) Lethal intestinal virus of infant mice is mouse hepatitis virus. Vet. Rec. 101, 465.

Carthew, P. (1978) Peroxidase-labelled antibody technique for the rapid detection of mouse hepatitis virus in cases of natural outbreaks. J. Infect. Dis. 138, 410413.

Carthew, P. (1981a) The pathogenesis of chronic viral hepatitis in the nude mouse and its influence on liver regeneration after partial hepatectomy. Br. J. exp. Path. 62, 631-637.

Carthew, P. (1981b) Inhibition of the mitotic response in regenerating mouse liver during viral hepatitis. Infection and Immunity 33, 641-642.

Carthew, P. \& Sparrow, S. (1981) Murine coronaviruses-the histopathology of disease induced by intranasal inoculation. Res. Vet. Sci. 30, 270-273.

Carthew, P. \& Verstraete, A. (1978) A serological survey of accredited breeding colonies in the United Kingdom for common rodent viruses. Lab. Anim. 12, 29-32.

Carthew, P., Gannon, J. \& Whisson, I. (1981) Comparison of alkaline phosphatase and horseradish peroxidase conjugated antisera in the ELISA test for antibodies to reovirus 3, mouse hepatitis and sendai virus. $L a b$. Anim. 15, 69-73.

Carthew, P., Wood, M.J. \& Kirby, C. (1983) Elimination of Sendai (parainfluenza type 1) virus infection from mice by embryo transfer. J. Reprod. Fert. 69, 253257.

Evans, M.J. \& Kaufman, M.H. (1981) Establishment in culture of pluripotential cells from mouse embryos. Nature, Lond. 292, 154-156.

Gannon, J. \& Carthew, P. (1980) Prevalence of indigenous viruses in laboratory animal colonies in the United Kingdom, 1978-1979. Lab. Anim. 14, 309 311.

Katami, K., Taguchi, F., Nakayama, M., Goto, N. \& Fujiwara, K. (1978) Vertical transmission of mouse hepatitis virus infection in mice. Jap. J.exp. Med. 48, $481-490$.
Manaker, R.A., Piczak, C.V., Miller, A.A. \& Stanton, M.F. (1961) A hepatitis virus complicating studies with mouse leukemia. J. natn. Cancer. Inst. 27, 29-51.

Mims, C.A. (1966) Immunofluorescence study of the carrier state and mechanism of vertical transmission in lymphocytic choriomeningitis virus infection in mice. J. Path. Bact. 91, 395-402.

Mohanty, S.B. \& Bachmann, P.D. (1974) Susceptibility of fertilised mouse eggs to minute virus of mice. Infection and Immunity 9, 762-763.

Neighbour, P.A. (1977) Susceptibility of the mouse preimplantation embryo to viral pathogenesis. Ph.D. thesis, University of London.

Nicolson, G.A., Yanagimachi, R. \& Yanagimachi, H. (1975) Ultra-structural localization of lectin binding sites on the zonae pellucidae and plasma membranes of mammalian eggs. J. Cell Biol. 66, 263-274.

Quinn, P., Barros, C. \& Whittingham, D.G. (1982) Preservation of hamster oocytes to assay the fertilizing capacity of human spermatozoa. J. Reprod. Fert. 66, 161-168.

Sebesteny, A. \& Hill, A.C. (1974) Hepatitis and brain lesions due to mouse hepatitis virus accompanied by wasting in nude mice. Lab. Anim. 8, 317-326.

Sokal, R.R. \& Rohlf, F.J. (1969) Biometry. W.H. Freeman and Co., San Francisco.

Tamura, T., Ueda, K., Hirano, N. \& Fujiwara, K. (1976) Response of nude mice to a mouse hepatitis virus isolated from a wasting nude mouse. Jap. J. exp. Med. 46, 19-30.

Tuffrey, M., Zisman, B. \& Barnes, R.D. (1972) Sendai (parainfluenza 1) infection of mouse eggs. Br. J. exp. Path. 53, 638-640.

Ward, J.M., Collins, M.J. \& Parker, J.C. (1977) Naturally occurring mouse hepatitis virus infection in the nude mouse. Lab. Anim. Sci. 27, 372-376.

Whittingham, D.G. (1971) Culture of mouse ova. $J$. Reprod. Fert. Suppl. 14, 7-21.

Whittingham, D.G. (1979) In vitro fertilization, embryo transfer and storage. Br. med. Bull. 24, 105-111.

Received 14 May 1984 